different healthcare systems but also within countries, again emphasising the considerable challenge of measurement of safety within this proposal.

In conclusion, this is a fascinating and intriguing proposal that merits wide debate. But is this proposal something that healthcare systems should take seriously and consider testing?

Could this approach dramatically improve safety within healthcare systems, or should we once again heed $\mathrm{HL}$
Mencken's view that "For every complex problem there is an answer that is clear, simple, and wrong"?

\section{Competing interests: None.}

Qual Saf Health Care 2009;18:83-84. doi:10.1136/qshc.2008.030379

\section{REFERENCES}

1. Coiera $\mathbf{E}$, Braithwaite J. Market-based control mechanisms for patient safety. Qual Saf Health Care 2009;18:99-103.
2. Chin MH, Wilkes AE. Equity concerns in market-based control schemes for patient safety. Qual Saf Health Care 2009; 18:88-90.

3. Donaldson C. Is safety safe in the market's hands? Qual Saf Health Care 2009;18:87-8.

4. Meltzer D. The Coase Theorem and patient safety. Qual Saf Health Care 2009;18:86-7.

5. Coiera E, Braithwaite J. Debating market-based control for patient safety: response to commentaries. Qual Saf Health Care 2009;18:90-1.

6. Hutchinson A, Young TA, Cooper KL, et al. Trends in healthcare incident reporting and relationship to safety and quality data in acute hospitals: results from the National Reporting and Learning System. Qual Saf Health Care 2009;18:5-10

\title{
The dangers of heparin flushes
}

\section{Brian Toft}

Heparin is undoubtedly a useful medicine in the battle against ill-health. However, besides being used for prophylaxis, heparin is also widely used to flush intravenous peripheral and central lines in an attempt to keep them patent.

\section{DANGERS ASSOCIATED WITH THE USE OF HEPARIN FLUSHES}

There is evidence to suggest that heparin flushes are a serious risk to patients without providing any commensurate benefits. For example, at a London hospital, vials containing several doses of the medicine were on two separate occasions administered in their entirety to two different patients. This resulted in the patients receiving 25000 IU of heparin rather than the intended dose of 5000 IU and requiring medical intervention to remedy the situation. Fortunately neither incident resulted in any long-term harmful effects. However, on another occasion this same error in the same hospital "resulted in death from cerebral haemorrhage". 1

More recently in the UK, four young patients were admitted to an acute trust's day bed unit to undergo diagnostic tests. As young children do not tolerate invasive procedures very well when awake, the tests were to be carried out under general anaesthesia. As part of the procedure the consultant paediatric anaesthetist was to administer a heparin flush. However, owing to human error and systems failures, each child was inadvertently administered 25000 IU of heparin-that is, a

Correspondence to: Brian Toft, 1 Gartons Road, Middleleaze, Swindon SN5 5TS, UK; brian.toft@ ntlworld.com dose 500 times greater than that which had been intended. None of the children involved in these incidents were reported to have experienced any lasting effects. However, the seriousness of these events cannot be overstated. Indeed, as a direct result of the author's report ${ }^{2}$ into these four patient safety incidents (PSIs) the UK's National Patient Safety Agency (NPSA) issued a "Rapid Response Report", warning the medical profession of the risk associated with heparin flushes. ${ }^{3}$

\section{EFFICACY OF HEPARIN FLUSHES}

The PSIs noted above illustrate that heparin flushes can carry considerable risk for patients. However, there does not seem to be any evidence that heparin flushes are more beneficial in keeping intravenous catheters and cannulas patent than flushing them with saline, particularly in adults. ${ }^{4}$

One of the reasons for the controversy regarding the efficacy of heparin flushes, particularly with regard to children, is the lack of research in this area. There are of course major ethical dilemmas in carrying out such studies on children and therefore the reluctance of the medical profession to pursue them is understandable. However, two studies in The Cochrane Central Register of Controlled Trials, one in neonates $^{5}$ and the other in the paediatric population, ${ }^{6}$ came to the conclusion that saline was just as effective as heparin in maintaining the patency of peripheral lines using cannulas. Another study on the "Treatment of catheter occlusion in paediatric patients" came to a similar conclusion.

With respect to the use of heparin flushes to maintain patency in central venous and arterial catheters the evidence is more problematic. Thus further research is urgently needed to clarify whether the benefits of using a heparin flush outweigh the risks, particularly with respect to children.

\section{VERBAL DOUBLE-CHECKING SAFETY PROTOCOLS}

Although "Human error is inevitable...", the Chief Medical Officer for England argues that "harm to patients is not". ${ }^{8}$ For example, if an inadvertent error is made by a healthcare professional but prevented from reaching the patient by a colleague then although an error was made no harm will have occurred-that is, a near-miss will have taken place as opposed to an iatrogenic event.

One potential way to reduce the risk of patients being harmed in healthcare settings is through the use of an explicit, appropriately configured, verbal doublechecking safety protocol. For example, the Human Fertilisation and Embryology Authority has made such protocols (known as "witnessing") mandatory in the UK. ' This is because such protocols can help identify inadvertent human errors and thus reduce the risks to patients. ${ }^{10}$ Similarly, it is considered best practice that prior to the administration of radiotherapy a verbal double-checking safety protocol of each patient's treatment parameters is undertaken by the radiographers.

Frequently, analogies are drawn between the medical profession and the commercial aviation industry. However, one major difference between the two professions, in terms of their operating procedures, is that whereas all aircrews must undertake verbal double-checking safety protocols, members of the medical profession do not. The UK commercial aviation industry has an excellent record for safety. For example, the UK Civil Aviation Authority has recently stated that ${ }^{11}$. 
"Provisional figures for 2007 show that UK large public transport aeroplanes carried approximately 128 million passengers.... During this time, UK large public transport aeroplanes were involved in seven accidents, none of which were fatal and none involved injuries to passengers or to crew on board the aircraft."

This safety record stands in stark contrast to the NPSA report that between January 2005 and June 2006, the National Reporting and Learning System received approximately 800 reports each month of errors relating to injectable medicines alone. During this period 25 patients lost their lives and there were 28 incidents of serious harm. ${ }^{12}$

It should be noted therefore that the safety record of the aviation industry has come about, in no small part, through the universal adoption of mandatory verbal double-checking safety protocols. ${ }^{13}$ Thus the introduction of such protocols might, as within the aviation industry, help to substantially reduce the numbers of inadvertent PSIs made by healthcare professionals.

Unfortunately, however, a verbal doublechecking safety protocol does not always prevent errors from being made or serious adverse events from occurring. Toft and Mascie-Taylor ${ }^{14}$ argue that the phenomenon of "involuntary automaticity", a mindset induced in healthcare professionals by their working conditions, can defeat even the most dedicated and meticulous checkers. The problem appears to arise because although the task that is the subject of the verbal double-checking safety protocol actually requires close attention, once it is captured by involuntary automaticity only a superficial amount of attentiveness is paid to the variables being checked. Therefore, if an error is present it can be missed without the individuals carrying out the safety protocol realising it. ${ }^{14}$

\section{CONCLUSIONS}

The dangers associated with large inadvertent overdoses of heparin are well documented; however, patients continue to experience harm, sometimes in the same hospital. Such events demonstrate that if the circumstances surrounding an unwanted event are allowed to replicate themselves then it is highly likely that another similar unwanted event will take place regardless of geographical location or time-that is, an "isomorphic failure" can take place. ${ }^{15}$ There seems to be no compelling medical evidence or advice from any quarter to suggest that a "heparin flush" is any more effective in keeping intravenous peripheral lines patent than a saline solution. This strongly suggests that heparin flushes should not be used in such circumstances, thereby reducing the risk of patients being administered an inadvertent overdose of this medicine.

A verbal double-checking safety protocol will not prevent all errors reaching a patient. However, the data discussed above in relation to healthcare and aviation do suggest that the implementation of such a procedure could reduce considerably the risk of inadvertent errors reaching a patient. This would seem to imply that healthcare professionals should, subject to their clinical judgement, carry out an explicit, appropriately configured verbal double-checking safety protocol when preparing and administering injectable drugs to patients, including heparin flushes.

\section{Competing interests: None.}

Qual Saf Health Care 2009;18:84-85.

doi:10.1136/qshc.2008.028324

\section{REFERENCES}

1. Kambal A, Najem M, Hussain TS. Multi-dosage vials, potential for overdose. Br J Clin Pharmacol 2004;58:677.

2. Toft B. Independent review of the circumstances surrounding four serious adverse incidents that occurred in the Oncology Day Beds Unit, Bristol Royal Hospital for Children on Wednesday, 3 January 2007. Search via http://www.who.int/patientsafety/ information centre/reports/Toft report Heparin.pdf (accessed $\overline{1} 2$ Sept 2008)

3. National Patient Safety Agency. Risks with intravenous heparin flush solutions. Rapid Response Report: NPSA/2008/RRR002. London: NPSA, 2008. Search via http://www.npsa.nhs.uk (accessed 12 Sept 2008)

4. Kaneko Y, Iwano M, Yoshida $\mathrm{H}$, et al. Natural salineflush is sufficient to maintain patency of immobilizedurokinase double-lumen catheter used to provide temporary blob access for hemodialysis. Blood Purif 2004;22:473-9.

5. Heilskov J, Kleiber C, Johnson K, et al. A randomized trial of heparin and saline for maintaining intravenous locks in neonates. J Soc Pediatr Nurs 1998;3:111-16.

6. Kleiber C, Hanrahan K, Fagan CL, et al. Heparin vs saline for peripheral i.v. locks in children. Pediatr Nurs 1993;19:405-9;376.

7. Kerner JA, Garcia-Careage AG, Fisher AA, et al. Treatment of catheter occlusion in pediatric patients. J Parenter Enteral Nutr 2006;30:73-81.

8. Department of Health. Dirty hands... the human cost. 2006 annual report of the Chief Medical Officer on the state of public health. London: DH, 2007:38.

9. Human Fertilisation and Embryology Authority. Standard: Witnessing the identification of samples and patients/donors. 5 April 2007:1. http://www.hfea. gov.uk/docs/2007-03 witnessing website linkstandard_and_guidance.pdf laccessed $1 \overline{2}$ Sept 2008).

10. Toft B. Independent review of the circumstances surrounding four adverse events that occurred in the Reproductive Medicine Units at The Leeds Teaching Hospitals NHS Trust, West Yorkshire. London: Department of Health, 2004:138. http://www.who. int/patientsafety/information_centre/reports/ Independent_review_Leeds.p.pdf laccessed 12 Sept 2008).

11. Civil Aviation Authority. Accident statistics. Safety management: incident reporting and investigation. Search via http://www.caa.co.uk laccessed 12 Sept 2008).

12. National Patient Safety Agency. Promoting safer use of injectable medicines. Patient Safety Alert 20. London: NPSA, 2007. http://www.npsa.nhs.uk/ EasySiteWeb/GatewayLink.aspx?alld=2269 (accessed 12 Sept 2008)

13. Bennett SA, Stewart N. Employees' experiences of, and attitudes towards teamworking at a National Health Services (NHS) District General Hospital. Risk Management 2007;:9:154

14. Toft B, Mascie-Taylor H. Involuntary automaticity: a work-system induced risk to safe health care. Healthc Serv Manage Res 2005;18:211-16.

15. Toft B. The failure of hindsight. Disaster Prevention and Management 1992;1:48-60. 